\title{
WestVirginiaUniversity
}

THE RESEARCH REPOSITORY @ WVU

Graduate Theses, Dissertations, and Problem Reports

2009

\section{An exploration of the reasons violent crimes are not reported to the police}

Sheena A. Marosy

West Virginia University

Follow this and additional works at: https://researchrepository.wvu.edu/etd

\section{Recommended Citation}

Marosy, Sheena A., "An exploration of the reasons violent crimes are not reported to the police" (2009). Graduate Theses, Dissertations, and Problem Reports. 4497.

https://researchrepository.wvu.edu/etd/4497

This Thesis is protected by copyright and/or related rights. It has been brought to you by the The Research Repository @ WVU with permission from the rights-holder(s). You are free to use this Thesis in any way that is permitted by the copyright and related rights legislation that applies to your use. For other uses you must obtain permission from the rights-holder(s) directly, unless additional rights are indicated by a Creative Commons license in the record and/ or on the work itself. This Thesis has been accepted for inclusion in WVU Graduate Theses, Dissertations, and Problem Reports collection by an authorized administrator of The Research Repository @ WVU. For more information, please contact researchrepository@mail.wvu.edu. 
An Exploration of the Reasons Violent Crimes are Not Reported to the Police.

\author{
Sheena A. Marosy \\ Thesis submitted to \\ Eberly College of Arts and Sciences \\ at West Virginia University \\ in partial fulfillment of the requirements \\ for the degree of
}

\author{
Master of Arts \\ in \\ Sociology
}

Approved by
Karen Weiss, Ph.D., Committee Chairperson
James J. Nolan III, Ph.D., Rachel Stein, Ph.D.
Division of Sociology and Anthropology
Morgantown, West Virginia
2009

Keywords: reasons for non-reporting, violent crime, victimization

Copyright 2009 Sheena A. Marosy 


\begin{abstract}
An Exploration of the Reasons Violent Crimes Do Not Get Reported to the Police.
\end{abstract}

Sheena A. Marosy

This paper explores the differences why violent crime victimizations are not being reported to the police. Using 2006 National Crime Victimization Survey (NCVS) data compiled by the U.S. Bureau of Justice Statistics, I develop and test cross-tabulation models which explain the influence age, sex, and victim/offender relationship has on the reporting of violent victimizations to the police. Previous research shows that victimizations involving males and juveniles are less likely to come to the attention of the police Results of my analysis support this research and show that older victims ages 26 and older are significantly more likely to report violent victimizations than younger victims ages 25 and under. Sex of the victim had no impact on whether or not crimes were reported to the police. Also, the relationship the victim has with the offender is significantly associated with the reason why these victims chose not to report the violent crime to the police. Males were more likely than females to state the reason for not reporting a violent crime is because it was minor, while females are more likely to state that the reasons they did not report a violent victimization was because of fear of reprisal. These findings are important to help address the reasons why victims may seek help from the police. 
Dedication

I would like to dedicate this work to my two dogs Rocko and Bear. 


\section{Acknowledgments}

This thesis could not have been written without the guidance of my thesis chair member Dr. Karen Weiss and the support of my committee members, Dr. James Nolan and Dr. Rachel Stein. Special thanks to the chair of my committee, Karen Weiss, who spent hours with me trying to make the National Victimization Survey manageable and who taught me a time-saving trick by using a syntax. I am also grateful to Loretta Price, who would talk to me for hours if I had any doubts about graduating and would make sure I had every piece of information filled out in time. I cannot forget all my teachers at West Virginia University who challenged and encouraged me to pursue graduate studies. Melissa Latimer, James Nolan, Corey Colyer, Jennifer Steele, Ronald Althouse, and Rachael Woldoff were all very supportive. I am also thankful to Daniel Brewster, who is not only an instructor, but who also became one of my closest friends. Without the support and encouragement of Daniel, I might not have finished my graduate studies. And, of course, I am infinitely grateful to my friends and family for all the love and support they have shown me. 
Table of Contents

$\begin{array}{ll}\text { Abstract } & \text { ii }\end{array}$

$\begin{array}{ll}\text { Dedication } & \text { iii }\end{array}$

Acknowledgments iv

Introduction 1

Review of Literature $\quad 5$

Crime Victimization 5

$\begin{array}{ll}\text { Age of the Victim } & 6\end{array}$

$\begin{array}{ll}\text { Life Course Theory } & 7\end{array}$

$\begin{array}{ll}\text { Gender of the Victim } & 8\end{array}$

Relationship to Offender 9

$\begin{array}{ll}\text { Reasons Not Reported } & 10\end{array}$

Factors in Underreporting 11

Methods 14

$\begin{array}{ll}\text { Objectives/Hypotheses } & 14\end{array}$

NCVS Data Overview 16

$\begin{array}{ll}\text { Operationalization of Variables } & 16\end{array}$

Dependent Variables 17

$\begin{array}{lr}\text { Independent Variables } & 18\end{array}$

$\begin{array}{ll}\text { Sample Statistics } & 21\end{array}$

$\begin{array}{ll}\text { Results } & 24\end{array}$

$\begin{array}{ll}\text { Reporting Rates } & 24\end{array}$

Reasons Not Reported 26 
Discussion

Conclusion

Appendix: Tables

References 


\section{INTRODUCTION}

One of the most important choices victims face in the aftermath of their victimization is the decision of whether or not to call the police. According to the results from the ongoing National Crime Victimization Survey (NCVS), there were almost 16 million criminal victimizations in the United States in 2006, and less than half of which were reported to the police. More specifically, $49 \%$ of violent victimizations were not reported, which included rape, robbery, and assault (Bureau of Justice Statistics, 2007). Without such notification, few crimes would come to the attention of the police.

Many of the past studies on violent victimizations have focused on comparing the rates of different types of victimizations between youth and adults using the National Victimization Crime Survey (NCVS). For instance, Hashima and Finkelhor (1999) conducted a study that compared the rates of violent victimizations between juveniles (12 to 17 years old) and adults (18 years and older). Some studies (Finkelhor and Ormrod 2001) have looked at the reasons for underreporting youth victimization to the police. However, few studies have looked to compare the reasons for reporting violent victimizations to the police among youth and adults.

This study is in response to Felson, Messner, Hoskin, and Deanes' (2002) study on the reasons for reporting and not reporting domestic violence to the police. More specifically, this study aims to explore the reasons why violent victimization incidents, including rape, robbery, and assaults are not reported to the police. A common assumption in the literature is that victims of violent crimes are reluctant to call the police (Felson et al. 2002, Greenberg and Beach 2004; Greenberg, Ruback, and Westcott 1982). This reluctance can be attributed to a variety of factors, such as age of the victim, gender of the victim, victim offender relationship. It can also be due to rationalizing situations as personal matter, minor crime, and fear of reprisal. 
Menard (2002) indicates that adverse effects (e.g., self-blame, depression) that potentially follow victimization experiences are prone to be more deleterious among juvenile victims, relative to adult victims, and therefore cause a reluctance to call the police. Therefore, gaining a better understanding of the disparity in police reporting between juvenile and adult victims would be advantageous.

In an attempt to better understand the contrasts between the experiences of juveniles and young adults (12 to 25 years old) and adults (26 years and older), I included the age of the victim in my analysis. Previous research has been done on the differences in reporting between juveniles and adults, including studies done by Hashima and Finkelhor, 1999, Finkelhor and Ormord, 2000 and 2001. Finkelhor and Ormrod (2001) found that juvenile victimizations are still less likely to be known to any authority ( $44 \%$ versus $55 \%$ than for adults). Also, previous research found that crimes against older persons are reported to the police more often than crimes against younger persons (Felson et al. 2002; Hart and Rennison 2003). In addition, Finkelhor and Ormord find that underreporting is also significantly associated simply with the age of the victim. Their analysis found that much violent victimizations are not reported to the police merely because they involve juvenile victims.

I included the gender of the victim in my analysis because gender is likely to be related to the likelihood of calling the police. For example, as previous literature shows, women are more likely than men to call the police (Felson et al. 1999; Gottfredson, M. R. and Gottfredson, D. M. 1980). Intimate partner violence has traditionally been constructed as an inherently "female" experience. Men who are abused contradict the dominant images of masculinity, and avoid asking for help or discussing the situation with others in order to live up to a masculine ideal (Migliaccio, 2002). Second, some research argues that women experience more severe abuse 
than men, leading them to seek help more often (Felson and Cares, 2005). This suggests that violent disputes between men tend to be handled privately.

Literature suggests that respondents are less likely to call the police when the offender in a violent incident is a partner or other family member than when the offender is a stranger (Block, 1974). On the other hand, a recent study based on the NCVS found that the victimoffender relationship had no effect on whether victims reported an assault to the police (Felson, Messner, and Hoskin, 1999). Bachman (1998), using the NCVS data, found that the relationship between the offender and victim did not affect the likelihood that the victim reported the rape to the police.

Respondents in the NCVS know that they are participating in a crime victimization survey, which may cause less reporting of incident they do not think of as crimes. As a result, incidents that are relatively minor are less likely to be included. However, once people consider themselves to be crime victims, previous research suggests that they are just as likely to call the police on family members, or someone else they know, as they are on strangers (Felson et al. 1999).

The previous research findings suggest that the effects of age, sex, and victim-offender relationship on victim reporting are more complex than previously thought. We explore these issues using the NCVS. In this survey, victims of violent crimes are asked whether the crime was reported to the police. Victims who reported an incident to the police were asked to explain why they did so, whereas victims who did not report the incident to the police were asked to explain why they chose not to report. For non-reporters, I looked to examine the motivation as it relates to the victims age, the victim's gender, and the relationship of the victim to the offender. 
For example, Skogan (1984) states, "A consistent finding of victim surveys is that crime reporting is relatively independent of personal attributes of victims." Thus, much existing research pertains to how victim/offender and situational characteristics affect variability in police reporting.

Results from the NCVS indicate that in 2006 less than half of all violent crimes were reported to the police. Violent crimes as defined by the NCVS include rape, assault, sexual assault, robbery, and verbal threats. Thus, this study focused on such crimes in an effort to further explore the effects of age, sex, and victim/offender relationship on reporting. My analyses go beyond previous works with the addition of what reasons victims give for not reporting violent crime to the police. Also, my analyses of reporting and reasons by age were then controlled for by gender. Victims are clearly selective in their reporting behavior. I then formulated several hypotheses, that based on previous reporting literature, were expected to increase the likelihood that victims would report a violent victimization to the police based on the age of the victim, the gender of the victim, and the victim's relationship to the offender. Increasing the prevalence of police reporting among victims may prove effective at preventing violence, for support services could be provided to victims especially prone to future involvement in violence 


\section{REVIEW OF LITERATURE}

Crime victimization throughout the stages of life has the tendency to be looked at differently. It has been well established, for example, that less serious crimes and crimes committed by acquaintances and family members are reported at lower rates (Finkelhor, Wolak, \& Berlinger 2001; Bachman 1998); and there may be differences across age groups. There are,

for example, cultural constructions that interpret violence against youth as more normal and less “crime-like" than it would be against adults (Finkelhor \& Kendall-Tackett 1997). For instance, when a juvenile is physically attacked by a peer, it may typically be seen as a fight or scuffle, even though the behavior is identical to acts that would be labeled criminal assaults were they to occur between adults (Finkelhor \& Ormrod 2001).

Across all age groups covered by the National Crime Victimization Survey (NCVS), Finkelhor, Wolak, and Berliner (2001) found that only forty-one percent of violent crimes are reported to the police.

Crime victimization data are not often presented in a way that contrasts the experience of youth and adults. Most of the past studies on violent victimizations that have compared the two groups have focused on comparing the rates of victimizations. For instance, Hashima and Finkelhor (1999) conducted a study that compared the rates of violent victimizations between youths (12 to 17 years old) and adults (18 years and older), and compared the rates of reporting of victimizations of youths and adults to the police. Hashima and Finkelhor (1999) found that the overall violent crime victimization for youth was 2.7 times higher than the rate for adults.

Hashima and Finkelhor (1999) also compared youth versus adult rates of reporting. They found that for the overall violent victimization perpetrated by a non-stranger, the percentage of reports was significantly lower for juveniles than for adults. Futhermore, the percentage of 
reporting to the police was lower for juvenile than for adult victimizations for both robbery and assault. Due to low reporting rates of victimizations for youths and adults, Hashima and Finkelhor (1999) also decided to briefly investigate the reasons for not reporting. They found that thirty-one percent of juveniles and twenty-one percent of adults answered that the most important reason for not reporting was that they felt the incident was not important enough to warrant a police notification.

Finkelhor and Ormord (2000) found that only twenty-eight percent of the violent crimes suffered by youth were reported to the police, compared to forty-eight percent of those suffered by adults. They also found that the underreporting of violent victimization to juveniles compared to adults holds across most categories of crime victimization. The one domain in which juvenile victims in the NCVS do not systematically report less to police compared to adults is the crime of sexual assault, and they found this is not because of increased reporting by juveniles but rather because of particular low levels of adult reporting, approximately thirty percent in each case (Finkelhor and Ormord, 2000).

Another study (Finkelhor and Ormrod 2001) looked at the reasons for underreporting youth victimizations to the police. This study examines reporting patterns and levels and evaluates the propositions that juvenile victimizations are less reported because they are less serious in nature than adult victimizations. They looked at the conditions that affect crime reporting to measure whether juvenile victimizations in terms of type of crime, injury, weapon use lead to lower reporting, or are they simply perceived as less serious and reported less because they happen to juveniles. In addition, in this study findings show that only twenty-eight percent of violent crimes against juveniles become known to the police compared to the forty-eight percent of crimes against adults that come to police attention. Clearly, juvenile victimizations are 
less likely to be reported than those of adults, a contrast that shows juveniles half as likely to have their victimizations reported (Finkelhor and Ormrod 2001). However, an important feature of juvenile victimization is that other authorities besides the police act as report receiving for these incidents. A substantial percentage of juvenile violent crime victimizations (16\%) are reported to other authorities. Even taking into account other forms of reporting, Finkelhor and Ormrod (2001) found that juvenile victimizations are still less likely to be known to any authority ( $44 \%$ versus $55 \%$ than for adults). They believe it may result from a mixture of attitudes on the part of the victims and victims' families: compassion for younger offenders, belief that police and school authorities do not have effective sanctions for young offenders, and skepticism that police will take such offenses seriously. In addition, Finkelhor and Ormord find that underreporting is also significantly associated simply with the age of the victim. Their analysis found that much violent victimizations are not reported to the police merely because they involve juvenile victims.

The life course perspective refers to a multidisciplinary paradigm for the study of people's lives, structural contexts, and social change. In this paper I integrated the research literature on the life course and crime. The relevance of social transitions in young adulthood and the factors and explaining desistance from crime as people age has been neglected.

Two central concepts underlie the analysis of life-course dynamics, a trajectory and a transition. A trajectory is a pathway or line of development over the life-span such as work life, marriage, parenthood, and self-esteem. Transitions are marked by specific life events (e.g. first job or first marriage) that are embedded in trajectories and evolve over shorter time spans (Elder, 1985, Sampson and Laub, 1990). The short-term view implies that transitions or turning points can modify life trajectories. The important institutions of social control vary across the life span: 
in childhood and adolescence these are the family, school, and peer groups; in the phase of young adulthood they are higher education and/or vocational training, work, and marriage; and in later adulthood, the dominant institutions are work, marriage, parenthood, and investment in the community (Sampson and Laub, 1990).

Informal social bonds to family and employment during adulthood explain changes in criminality over the life span despite early childhood propensities (Sampson and Laub, 1990, 1992). Sampson and Laub find that attachments or social bonds in adulthood increase some individuals' social capital, leading to desistance from most types of deviant behavior. Men who become attached to coworkers or a spouse will increase their self-control; alternatively, as Gottfredson and Hirschi (1990) hypothesize that marriage per se does not increase social control, (Sampson and Laub, 1990) believe that a strong attachment to one's spouse and close emotional ties increase the social bond between individuals and, all else equal, should lead to a reduction in criminal behavior. Similarly, employment by itself does not increase social control. It is employment coupled with job stability, job commitment, and ties to work that should increase social control and, all else equal, lead to a reduction in criminal behavior.

I am interested in using this theory to investigate the rate of reporting violent crimes to the police and whether or not age is a factor. I hope to relate lower criminal behavior to higher reporting rates and I anticipate finding that higher rate in the adult age because of the turning points in their life.

In addition to age on reporting, gender may also contribute. According to Skogan (1984), sex differences in reporting are small, but consistent; with women more likely than men to report, even when controlling for type of crime. 
Differences in police reporting behaviors may be understood in terms of a broader gender ideology. Intimate partner violence has traditionally been constructed as an inherently "female" experience. Men who are victimized contradict the dominant images of masculinity, and avoid asking for help or discussing the situation with others in order to live up to a masculine ideal (Migliaccio, 2002). Second, some research argues that women experience more severe abuse than men, leading them to seek help more often (Felson and Cares, 2005). Third, dependency on one's partner may also influence the decision to call the police. Research suggests that individuals who are financially dependent on the abuser are less likely to call the police (Rollwagen and Van Brunschot 2007).

While the existing research provides some explanation for gender differences, there is little empirical research that compares a similar set of predictors of reporting behaviors by gender. In Rollwagen and Van Brunschot (2007), evidence further shows that there are gender differences in reporting behaviors. The variables included in their logistic regression model account for 33 percent of the variation in men's reporting behaviors; however, the same variables only account for 12 percent of the variation in women is reporting behaviors. The variables included in their study were severity of violence, perceptions of police, education, and marital status. This research illustrates the clear gender differences in reporting behaviors. Results show that women are much more likely than men to report intimate partner violence to the police.

It has been well established that less serious crimes and crimes committed by family members are reported at lower rates (Bachman, 1998; Finkelhor, Wolak, \& Berlinger, 2001) and there may be differences across age groups. Finkelhor et al. (2001) found in their study that only $41 \%$ of violent crimes are reported to the police. Felson, Messner, Hoskin, and Deane (2002), sum up what Black (1976) explains in his article by stating that the closer the relationship 
between adversaries, the less likely it is that the victim will report the incident to the police.

Surveys have shown that victims are less likely to call the police when the antagonist in a violent incident is a partner or other family member than when they are a stranger (Block, 1974). However, another analysis based on the NCVS found that the victim-offender relationship had no effect on whether victims reported to the police (Felson, Messner, and Hoskin 1999). Also, Felson et al. (1999) report that once people consider themselves to be crime victims, they are just as likely to call the police on family members, or someone else they know, as they are on strangers.

Victims of violent crimes may be reluctant to call the police because of their social ties to the offender and because they want to protect their offender from criminal prosecution. Thus, victims of acquaintances or strangers should be more likely than victims of violence by family members or partners to call the police because of their lack of desire to protect the offender. Also, women may be more likely to protect their male partners, which is consistent with reasons why women are unwilling to assist in prosecution. Women may not want to get their partners in trouble because of their desire to continue in the relationship for either emotional or economic reasons (Felson et al. 2002).

Again, the relationship between the offender and the victim may affect perceptions of the severity of the offense. According to Straus, Gelles, and Steinmetz (1980), violent acts committed by family members are more likely to be tolerated than violence committed by offenders outside the family.

Reasons

There are a number of reasons why victims do not report crime to the police. Many victims view the crime event as one that is best dealt with another way, reflecting a belief that 
the crime is too minor to report or that the police could not do anything about it (Gartner \& Doob, 1994). Felson et. al (2002) suggests reasons that are likely to inhibit victims from calling the police. First, victims may be concerned about embarrassment and status. The most common reason victims give for not calling the police, according to the analyses of the $2006 \mathrm{NCVS}$, is that the violent incident was a private/personal matter. Victims are sometimes embarrassed because they believe that their association with a violent partner or family member will stigmatize them. Second, victims may avoid calling the police because they want to protect the offender from criminal prosecution. This reason goes along with the previous factor because they may want to protect a violent partner or family member because of their association with the offender. Third and finally, victims may not call the police because of their fear of reprisal. They may be afraid that their offender will respond back with physical violence or some nonviolent form of retaliation. Prior research results suggest that reprisal was more often a factor in personal victimizations where victims were female and acquainted with their offenders. The more dangerous the incident, the more often reprisal was the stated reason for not calling the police. Interestingly, NCVS respondents frequently give fear of reprisal as a reason for not reporting violent crimes to the police.

Finkelhor and Ormord (2001) also determined reasons why crimes with child victims may be underreported to the police. They were categorized as follows: definitional, jurisdictional, developmental, emotional/attitudinal, and material. The first three categories apply to the situations of juveniles, whereas the last two may be applied to the underreporting of adults as well.

Definitional factors concern whether acts are seen as crimes, serious violations, or anything that would be of potential interest to the police. Crimes involving young people are 
sometimes viewed as a "normal" part of youth, "learning experiences" rather than crimes. These crimes are not defined by victims or parents as crimes that fall within police jurisdiction. Specifically, Hashima and Finkelhor (1999) found in the NCVS reports that thirty-one percent of juvenile victimizations, compared to twenty-one percent of adult victimizations, were not reported to the police because of reasons coded under the heading "not important enough to report."

Jurisdictional factors have to do with what authority may initially take charge of the handling of victimizations. For example, crimes against children may be handled directly by parents, school officials, and child protective services instead of being passed on to the police. Finkelhor and Ormord (2000) confirm with NCVS data the existence of alternative jurisdictions for crimes against children. About thirty-nine percent of violent crimes against children that are not reported to the police are "dealt with another way," that is, reported to another authority or handled informally.

Developmental reasons highlight the barriers young children have to reporting. First, youth may not have direct access to police but must do so through the interaction of adults. Adult victims generally determine whether their victimization will be revealed to the police. For a child's victimization to be reported the child generally has to disclose to an adult and the adult has to make the report.

Emotional/attitudinal reasons are individual reactions that inhibit or motivate victims and their families to report child victimizations to authorities when an incident is defined as victimization. In adult studies, victims' concerns about reporting have ranged from fear of embarrassment to fear of retaliation by the perpetrator. Fear of retaliation may be considered 
important among victims who may not be confident that the police or other authorities can protect them from their offenders.

Material reasons voiced by victims were about the time and financial losses that may be incurred. There has been little examination of this factor, especially concerning juvenile victims. However, the extent to which parents need to be with children in their encounters with the justice system may be a factor. 


\section{METHODS}

\section{Objective/Hypotheses}

This study is interested in comparing the reporting rates and the reasons violent crimes were not reported to the police by age, sex, and victim/offender relationship. It is expected that the rates of reporting and the reasons will vary among different age groups and that the older you are, the more likely you are to report a crime. There are two general objectives. In this first section, I will examine the reporting rates of violent victimizations to the police, and to measure the impact that victim's age, gender, and victim/offender relationship have on reporting rates. The second objective is to examine the reasons for not reporting victimization to the police.

Three hypotheses were developed to test various conditions that, based on previous reporting literature, were expected to increase the likelihood that victims would report victimizations to the police.

\section{Hypothesis One}

Violent crimes are more likely to be reported to the police when the victim is an adult. Juveniles are less likely to report violent crimes to the police because they will feel it is a personal matter, fear reprisal, and/or they feel it is too minor to report as a crime.

This hypothesis is based on the previous research that victimizations will be more likely reported when the incident has happened to an adult victim, when compared to a juvenile (Hashima and Finkelhor 1999). Hashima and Finkelhor (1999) found that juveniles reporting rate was significantly lower than that of adult victims for both robbery and assaults. The one exception they found was that reporting rate for juveniles was higher than the adult rate was for rape/sexual assaults. Finkelhor and Ormord (2001) findings show that only twenty-eight percent 
of violent crimes against juveniles become known to the police compared to the forty-eight percent of crimes against adults that come to police attention. Finkelhor and Ormord believe the lower rate of reporting may be the result of a mixture of attitudes on the part of the victims and victims' families: compassion for younger offenders, belief that police and school authorities do not have effective sanctions for young offenders, and skepticism that police will take such offenses seriously.

\section{Hypothesis Two}

Violent crimes are more likely to be reported to the police when the victim is a female. Males are less likely report violent crimes to the police because they feel it is a personal matter, and they feel it is too minor to report. Females will be less likely to report because of a fear of reprisal. Research suggests that crimes involving male victims are less prone than crimes involving female victims to come to the attention of the police (Felson et al. 2002; Hart and Rennison 2003; Laub 1997). Felson and Cares (2005) argue that women experience more severe abuse than men, leading them to seek help more often.

\section{Hypothesis Three}

Victims who have a prior intimate or family-like relationship with the offender are less likely to define the victimization as a crime and to report it to the police.

This last hypothesis is based on the assumption that victims will be more willing to excuse certain offenders such as a family member or intimate partner. Koss, Dinero, Seibel, and Cox (1988) found that victims of acquaintance rape were less likely than victims of stranger rape to label the attack as rape and to report it to the police. Also, data from the NCVS indicates that 
approximately twenty percent of victims of a violent crime were more likely to say they did not report because it was a "private matter."These kinds of personal concerns are more likely to be present if there was or is some type of relationship between the victim and the offender.

\section{NCVS Data Overview}

The data set used for this study consists of 1775 violent crime incidents collected from the National Crime Victimization Survey (NCVS) during the year 2006. The NCVS is administered by the U.S. Census Bureau for the Bureau of Justice Statistics. The survey is the nation's primary source of information on criminal victimization. The NCVS has been conducted since 1973 to obtain detailed information about the victims and consequences of crime in the United States. In addition to demographic information, such as age, gender, ethnicity, and income, the NCVS gather information on the relationship between victim and offender, whether the crime was reported to the police, and reasons for not reporting.

Each year, data are obtained from a nationally representative sample of 76,000 households comprising nearly 135,300 persons, ages 12 and older. Each month the U.S. Bureau of the Census selects respondents for the NCVS using a "rotating panel" design. Households are randomly selected, and all age-eligible individuals in a selected household become part of the panel. The NCVS has consistently obtained a response rate of about 95\% (Bureau of Justice Statistics 2008).

\section{Operationalization of Variables}

Variables from the NCVS were operationalized to quantitatively analyze patterns and to test the hypotheses outlined earlier. Hypotheses predicted that reporting to the police would be 
most likely when 1) victims were part of the adult age group; 2) victims were female; and 3) victims did not know their offender. Also, hypotheses predicted that there would be a difference between the reasons for not reporting to the police because of 1) the victim's age; 2) the victim's gender; and 3) the victim/offender relationship.

The sections to follow outline variable selection and operationalization, starting with the study's dependent variables: 1) reporting to the police (yes/no); 2) reasons for not reporting; and then outlining the three categories of independent variables: 1) the victim's age; 2) the victim's gender; and 3) the victim/offender relationship.

\section{Dependent Variables}

\section{Reported to the Police (yes/no)}

Reporting to the police was examined as a dependent variable in order to test whether any of our independent variables, age, gender, and victim/offender relationship has any effect on the decision to report to the police. The variable was coded as: reported to the police (1) and not reported to the police (0). Incidents (32) where the victims did not know whether the victimization was reported to the police were added to the category, not reported to the police.

\section{Reasons Not Reported}

Respondents were asked what the reason was that the incident was not reported to the police. They were given example reasons, such as, "Was the reason because you dealt with it another way, it wasn't important enough to you, police couldn't help, etc?" A frequency was run for the variable, "the most important reason for not reporting." The top three were, "it was a minor crime," "it was a personal matter," and "fear of reprisal." I chose these top reasons, which 
were then cross tabulated against my independent variables to look for any significant differences.

\section{Personal Matter}

Respondents were asked, "Did you not report to the police because you dealt with it another way; was it a private or personal matter, or did you take care of it yourself or informally by telling the offender's parents?" The variable was coded as: no (0) and yes (1).

\section{Minor Crime}

Respondents were asked whether the incident was not important enough to report, whether the crimes was minor or unsuccessful, and if there was small or no loss. The variable was coded as: no (0) and yes (1).

\section{Fear of Reprisal}

Respondents were asked whether they were afraid to report the victimization because of a reprisal by the offender or others. The variable was coded as no (0) and yes (1).

\section{Independent Variables}

\section{Age}

Research has found that crimes against older persons are reported to the police more often than crimes against younger persons (Felson, Messner, Hoskin, and Deane 2002). This paper will examine the reporting rates and reasons to identify the differences between age groups. To assess the respondents age, the respondent was asked how old they were at the time 
of the victimization. The age variable was re-coded into two categories for this study. Ages 25 and under $=1$ and ages 26 and older $=0$. The categories were separated to determine differences between age groups. Ages 25 and under can be described as juvenile/young adults. Ages 26 and older can be described as adults. The important institutions of social control vary across the life span: in childhood and adolescence, these are the family, school, and peer groups; in the phase of young adulthood, they are higher education and/or vocational training, work, and marriage; and in later adulthood, the dominant institutions are work, marriage, parenthood, and investment in the community (Sampson and Laub, 1990).

Ages 25 and under is an important demarcation because it includes juveniles and young adults. This age group marks significant changes in lifestyles and responsibilities. Juveniles and young adults begin to encounter a number of issues as they finish school and begin to hold fulltime jobs and take on other responsibilities of adulthood. Young adults become individuals and will begin to set themselves apart. Young adults will strive to become independent from parents, take responsibility for themselves and make their own decisions. During the adult stage (26 and older), the majority think in a more mature manner and take issues more seriously. They focus on the construction of a better future. The adult stage is often characterized by having responsibility, experience, a decision-making capability, and priorities. This can be linked back to the life course theory used by Sampson and Laub (1990) which stated that strong attachments in adulthood, for example, employment coupled with job stability, commitment, and ties to work should increase social control and lead to a reduction in crime, and lead to higher reporting rates. 


\section{Gender}

Research suggests that crimes involving male victims or younger offenders are less prone than crimes involving female victims or older offenders to come to the attention of the police (Felson et al. 2002). Men tend to be bigger and stronger than women, more skillful in physical combat, and more willing to use violence, and as a result, female victims should be more likely to call the police for more protection than they should be more likely to call the police for more protection than male victims (Felson et al. 2002). Singer (1988) found that women were more likely to fear reprisals than men.

According to Felson (1996), men who have been assaulted may view the offense as less serious than women who have been assaulted. In addition, male victims should be more likely than female victims to think that the assault was too minor to report (Felson et al. 2002). To assess the respondent's gender, interviewers marked down either male or female.

\section{Victim/Offender Relationship}

Victims of violence by partners and family members should be more likely than victims of acquaintances or strangers to be inhibited from calling the police by their desire to protect the offender (Felson et al. 2002). Felson et al. (2002) found that victims are more than five and onehalf times more likely to protect partners and more than eight times more likely to protect other family members than they are strangers who assault them. According to Strauss et al. (1980), violent acts committed by family members are more likely to be tolerated than violence committed by offenders outside the family. Hart and Rennison (2003) found that 41 percent of violent crimes perpetrated by non-strangers were reported to the police, compared with 45 percent of violent crimes perpetrated by strangers. After disaggregating the non-stranger 
category, Hart and Rennison (2003) further revealed that only 36 percent of violent crimes perpetrated by friends and acquaintances were reported to the police.

To assess if the respondent knew the offender, the respondent was asked, "Would you be able to recognize the offender is you saw him/her? If the response was affirmative, the respondent then was asked, "How well did you know the offender? By sight only, casual acquaintance or well known?" If the victim knew the offender well, the respondent was asked, "How did you know the offender? For example, was the offender a friend, cousin, and so on?"

The responses were categorized as: spouse at the time of the incident, ex-spouse at the time of the incident, parent or stepparent, own child or stepchild, sibling, boyfriend, girlfriend, or ex-boy/girlfriend, friend or ex-friend, roommate, schoolmate, neighbor, and someone at work or customer. For this study, based on prior research, a victim/offender relationship variable for victim/offender relationship was re-coded as family/intimates $=1$, friends/acquaintance $=2$, and stranger/sight only $=3$. The family/intimate category was someone well known to the victim, which included relatives, such as parents or siblings; and intimates, such as spouses, or boyfriends and girlfriends, including exes. The friend/acquaintance category was someone the victim knew well enough to say more than "hello" to, which included friends, ex-friends, schoolmate, or roommates. Finally, the stranger/sight only category was someone the victim had never seen before or someone they had not said more than "hello" to. This category included strangers, and customers or clients at work.

\section{Sample Statistics}

As measured by the NCVS, violent crime encompasses rape, sexual assault, robbery, aggravated assault, and simple assault (defined below). Murder is not measured by the survey 
because of the inability to interview murder victims. Therefore, the "violent crime" category includes six categories: "rape”, "sexual assault," "aggravated assault," “assault," “verbal threats," and "robbery." For the purposes of this study, all other crimes were excluded from this study as only looking at "violent" crimes.

Violent victimization incidents in this sample include 48 rapes (defined as forced sexual intercourse means vaginal, anal, or oral penetration by the offender and included completed and attempted rapes), 16 sexual assaults (defined as an attack or attempted attack generally involving (unwanted) sexual contact between victim and offender. Sexual assaults may or may not involve force and included sexual attack with serious or minor assault, sexual assault without injury, and unwanted sexual contact without force), 212 aggravated assaults (defined as an attack or attempted attack with a weapon, regardless of whether or not an injury occurred, and attack without a weapon when serious injury results), 819 assaults/simple assaults (defined as an attack without a weapon resulting either in minor injury (e.g., bruises, black eyes, cuts, scratches, swelling) or in undetermined injury requiring less than two days of hospitalization. Attempted assault without a weapon was also included in the category of assault, and 493 verbal threats (included threats of rape, sexual assault, and assaults). Finally, 187 robbery accounts (defined as the taking or attempting to take anything of value from the care, custody, or control of a person or persons by force or threat of force or violence and/or by putting the victim in fear from another person by force or threat of force) were included in this sample.

\section{Data Analysis}

Analyses of statistical relationships between accounts of reporting and independent variables were conducted by cross-tabulating (in SPSS) reporting (yes/no) by victim's age, 
victim's gender, and victim/offender relationship. Also, crosstab analyses were conducted to determine whether there were differences between juvenile and adult reasons for not reporting violent crimes to the police. The significance of variable relationships was examined using the chi-square statistic. The tables from the bivariate tests can be found in the appendix. 


\section{RESULTS}

In the appendix, table 1 reports descriptive statistics. The sample used for this study's analysis consists of 1775 violent victimization incidents during the year 2006. Approximately $48 \%(n=852)$ of the victims reported the violent crime to the police, whereas $52 \%(n=923)$ did not report. $23.3 \%$ reported the reason for not reporting the crime was because of a personal matter, $19.6 \%$ reported the reason was because the crime was too minor, $9.8 \%$ reported the reason for not reporting was because of a fear of reprisal, and $47.3 \%$ reported the reason was other. The sample had the following characteristics: $40.1 \%$ of respondents were twenty-five years of age and younger, while $59.9 \%$ were 26 years of age or older. $51.2 \%$ of the respondents were male, whereas $48.8 \%$ were female. $80.1 \%$ of the victims for whom race could be determined are white, $13.2 \%$ are black, and $6.8 \%$ are other races. $12.8 \%$ of the sample's respondents for whom Hispanic/non-Hispanic origin could be determined are of Hispanic origin, while $87.2 \%$ are not of Hispanic origin.

\section{Reporting}

Juvenile/young adult versus adult rates of reporting. Table 2 shows the overall reporting rates for juvenile/young adult victims ages 25 and under and adult victims ages 26 and older in 2006. As we can see, adult victims are more likely to report violent crimes to the police than juveniles. For example, 53.4 percent of adult victims say they reported a violent crime to the police, compared to 40.1 percent of juveniles, $\chi^{2}=30.061, \mathrm{df}=1, \mathrm{p}<.001$. Age of the victim has a great impact on whether a violent crime is reported to the police and the relationship can be considered statistically significant. 
Male versus female rates of reporting. Table 2 shows the overall reporting rates male victims and female victims in 2006. As we can see, female victims are more likely to report violent crimes to the police than male victims. For example, 50.3 percent of female victims say they reported a violent crime to the police, compared to 45.8 percent of males, $\mathrm{p}<.059$. With a chi square value ( $\chi^{2}$ of 3.556 and degrees of freedom as 1$)$, I found that the sex of the victim has a weak impact on whether a violent crime is reported to the police and the relationship can be considered not statistically significant.

Victim/Offender relationship rates of reporting. Table 2 shows the overall reporting rates based on the relationship the victim had to the offender in 2006. As we can see, victims whose relationship to the offender is family/intimate or a sight only/stranger are more likely to report violent crimes to the police than the friend/acquaintance relationship. For example, 52.6 percent of victims whose relationship to the offender is family/intimate say they reported a violent crime to the police, 51.1 percent of victims whose relationship to the offender is sight only/stranger say they reported a violent crime to the police, compared to 34.2 percent of victims whose relationship to the offender was friend/acquaintance, $p<.001$. With a chi square value $\left(\chi^{2}\right.$ of 33.884 and degrees of freedom as 2), I found that the relationship the victim has with the offender has a great impact on whether a violent crime is reported to the police and the relationship can be considered statistically significant.

Juvenile/young adult versus adult rates of reporting by controlling for sex. Table 3 shows the overall reporting rates for juvenile/young adult victims ages 25 and under and adult victims 26 and older by sex in 2006. As we can see, female adult victims are not significantly more likely to report violent crimes to the police than male adult victims. For example, 54.2 percent of female adult victims say they reported a violent crime to the police, compared to 52.5 percent of 
male adult victims. However, female juvenile victims are significantly more likely to report violent crimes to the police than male juvenile victims. For example, 44.3 percent of female juvenile victims say they reported a violent crime to the police, compared to 36.3 percent of male juvenile victims, $\mathrm{p}<.001$. With a chi square value $\left(\chi^{2}\right.$ of 23.316 and degrees of freedom as 1 for males and $\chi^{2}$ of 8.112 and degrees of freedom as 1 for females), I found that when controlling for sex, the age of the victim has a great impact on whether a violent crime is reported to the police and the relationship can only be considered statistically significant for juveniles but not for adults.

\section{Reasons}

Juvenile/young adult versus adult rate for reason not reported: personal matter. Table 4 shows the overall rates for the reason not reported to the police: as a personal matter, for juvenile victims ages 25 and under and adult victims 26 and older in 2006. As we can see, adult victims are no more likely to say the reason for not reporting the violent crime was because of a personal matter compared to juvenile victims. For example, 24.4 percent of adult victims say they never reported a violent crime to the police, compared to 22.1 percent of juvenile victims. The chi square value ( $\chi^{2}$ is a value of 0.641 and degrees of freedom is 1$)$. However, from this I can state that the age of the victim has a weak impact on reporting a violent crime to the police for the reason of a personal matter and the relationship can be considered not statistically significant. Juvenile/young adult versus adult rate for reason not reported: minor crime. Table 4 shows the overall rates for the reason not reported to the police: as a minor crime, for juvenile victims ages 25 and under and adult victims 26 and older in 2006. As we can see, juvenile/young adult victims are no more likely to say the reason for not reporting the violent crime was because 
of a minor crime compared to adult victims. For example, 21.0 percent of juvenile victims say they never reported a violent crime to the police, compared to 18.5 percent of adult victims. The chi square value $\left(\chi^{2}\right.$ is 0.866 and the degree of freedom is 1$)$. Age of the victim has a weak impact on the reason: minor crime has on reporting a violent crime to the police and the relationship can be considered not statistically significant.

Juvenile/young adult versus adult rate for reason not reported: fear of reprisal. Table 4 shows the overall rates for the reason not reported to the police: fear of reprisal, for juvenile/young adult victims ages 25 and under and adult victims 26 and older in 2006. As we can see, juvenile victims are no more likely to say the reason for not reporting the violent crime was because of a minor crime compared to adult victims. For example, 10.5 percent of juvenile victims say they never reported a violent crime to the police, compared to 9.1 percent of adult victims. There is a chi square value $\left(\chi^{2}\right.$ of 0.457 and degrees of freedom is 1$)$. I found that the age of the victim has a weak impact on the reason: fear of reprisal has on reporting a violent crime to the police and the relationship can be considered not statistically significant.

Male versus female rate for reason not reported: personal matter. Table 4 shows the overall rates for the reason not reported to the police: personal matter, for male victims and female victims in 2006. As we can see, male victims are no more likely to say the reason for not reporting the violent crime was because of a personal matter compared to female victims. For example, 24.4 percent of male victims say they never reported a violent crime to the police, compared to 22.1 percent of female victims. With a chi square value ( $\chi^{2}$ of 0.659 and degrees of freedom as 1), I found that the sex of the victim has a weak impact on the reason: personal matter has on reporting a violent crime to the police and the relationship cannot be considered statistically significant. 
Male versus female rate for reason not reported: minor crime. Table 4 shows the overall rates for the reason not reported to the police: minor crime, for male victims and female victims in 2006. As we can see, male victims are more likely to say the reason for not reporting the violent crime was because it was a minor crime compared to female victims. For example, 26.3 percent of male victims say they never reported a violent crime to the police, compared to 12.0 percent of female victims, $p<.001$. With a chi square value $\left(\chi^{2}\right.$ of 28.719 and degrees of freedom as 1), I found that the sex of the victim has a strong impact on the reason: minor crime has on reporting a violent crime to the police and the relationship can be considered statistically significant.

Male versus female rate for reason not reported: fear of reprisal. Table 4 shows the overall rates for the reason not reported to the police: fear of reprisal, for male victims and female victims in 2006. As we can see, female victims are more likely to say the reason for not reporting the violent crime was because of fear of reprisal compared to male victims. For example, 13.9 percent of female victims say they never reported a violent crime to the police, compared to 6.1 percent of male victims, $p<.001$. With a chi square value $\left(\chi^{2}\right.$ of 15.459 and degrees of freedom as 1), I found that the sex of the victim has a strong impact on the reason: fear of reprisal has on reporting a violent crime to the police and the relationship can be considered statistically significant.

Victim/Offender relationship rate for reason not reported: personal matter. Table 4 shows the overall rates for the reason not reported to the police: personal matter, based on the victim/offender relationship in 2006. As we can see, victims whose relationship to the offender is family/intimate are more likely to say the reason for not reporting the violent crime was because of it was a personal matter compared to victims whose relationship is a friend/acquaintance or 
sight only/stranger. For example, 33.3 percent of victims whose relationship to the offender is family/intimate say they never reported a violent crime to the police, compared to 26.9 percent of victims whose relationship is friend/acquaintance, and 18.6 percent of victims whose relationship is sight only/stranger, $\mathrm{p}<.001$. With a chi square value $\left(\chi^{2}\right.$ of 16.759 and degrees of freedom as 2), I found that the relationship to the offender has a strong impact on the reason: personal matter on reporting a violent crime to the police and the relationship can be considered statistically significant.

Victim/Offender relationship rate for reason not reported: minor crime. Table 4 shows the overall rates for the reason not reported to the police: minor crime, based on the victim/offender relationship in 2006. As we can see, victims whose relationship to the offender is sight only/stranger are more likely to say the reason for not reporting the violent crime was because of it was a minor crime compared to victims whose relationship is a friend/acquaintance or family/intimate. For example, 24.2 percent of victims whose relationship to the offender is sight only/stranger say they never reported a violent crime to the police, compared to 13.7 percent of victims whose relationship is friend/acquaintance, and 13.8 percent of victims whose relationship is family intimate, $\mathrm{p}<.001$. With a chi square value $\left(\chi^{2}\right.$ of 15.075 and degrees of freedom as 2), I found that the relationship to the offender has a moderate impact on the reason: minor crime on reporting a violent crime to the police and the relationship can be considered statistically significant.

Victim/Offender relationship rate for reason not reported: fear of reprisal. Table 4 shows the overall rates for the reason not reported to the police: fear of reprisal, based on the victim/offender relationship in 2006. As we can see, victims whose relationship to the offender is family/intimate are more likely to say the reason for not reporting the violent crime was because 
of it was a personal matter compared to victims whose relationship is a friend/acquaintance or sight only/stranger. For example, 13.8 percent of victims whose relationship to the offender is family/intimate say they never reported a violent crime to the police, compared to 9.7 percent of victims whose relationship is friend/acquaintance, and 8.5 percent of victims whose relationship is sight only/stranger, $\mathrm{p}<.001$. With a chi square value ( $\chi^{2}$ of 3.889 and degrees of freedom as 2 ), I found that the relationship to the offender has a weak impact on the reason: fear of reprisal on reporting a violent crime to the police and the relationship cannot be considered statistically significant.

Reason not reported: personal matter by age and controlling for sex. Table 5 shows the overall reporting rates for juvenile victims ages 25 and under and adult victims 26 and older by sex in 2006. As we can see, female juvenile victims are no more likely to say they did not report a crime because of personal matter compared to male juvenile victims. For example, 23.8 percent of female juvenile victims say they never reported a violent crime to the police because of a personal matter, compared to 20.9 percent of male juvenile victims. Also, male adult victims are no more likely to say they never reported a violent crime to the police than female adult victims. For example, 27.9 percent of male adult victims say they reported a violent crime to the police, compared to 20.8 percent of female adult victims. I found that age when controlled for sex has a weak impact on whether a violent crime is not reported to the police because of personal matter and the relationship cannot be considered statistically significant.

Reason not reported: minor crime by age and controlling for sex. Table 5 shows the overall reporting rates for juvenile victims ages 25 and under and adult victims 26 and older by sex in 2006. As we can see, male juvenile victims and male adult victims are more likely to say they did not report a crime because it was minor compared to female juvenile victims and female 
adult victims. For example, 28.5 percent of male juvenile victims say they never reported a violent crime to the police because it was a minor crime, compared to 11.4 percent of female juvenile victims. Also, male adult victims are more likely to say they never reported a violent crime to the police than female adult victims. For example, 24.2 percent of male adult victims say they reported a violent crime to the police, compared to 12.6 percent of female adult victims. There is a chi square value ( $\chi^{2}$ of 1.155 and the degrees of freedom is 1$)$. I found that the sex and the age of the victim has a weak impact on whether a violent crime is to reported to the police because it was a minor crime and the relationship can be considered statistically non-significant.

Reason not reported: fear of reprisal by age and sex. Table 5 shows the overall reporting rates for juvenile victims ages 25 and under and adult victims 26 and older by sex in 2006 . As we can see, female juvenile victims and female adult victims are more likely to say they did not report a crime because of fear of reprisal compared to male juvenile victims and male adult victims. For example, 13.0 percent of female juvenile victims say they never reported a violent crime to the police because it was a minor crime, compared to 14.7 percent of female adult victims. Also, female adult victims are more likely to say they never reported a violent crime to the police than male adult victims. For example, 8.5 percent of male juvenile victims say they reported a violent crime to the police, compared to 3.8 percent of male adult victims, $\mathrm{p}<.05$. The chi square value ( $\chi^{2}$ is 4.694 and the degree of freedom is 1$)$. I found that the sex and the age of the victim has a moderate impact on whether a violent crime is not reported to the police because of fear of reprisal and the relationship can be considered statistically significant. 


\section{DISCUSSION}

Age of Victim

I predicted that violent crime victimizations would more likely be reported to the police when the victim is an adult. As predicted, crimes involving victims who are adults, ages 26 and older, are more likely to be reported to the police after they were victimized compared to crimes that involve juveniles, ages 25 and under.

Older respondents compared to younger to feel they have a social responsibility to report crimes to the police. This can be supported by Finkelhor and Ormord's factors for underreporting. First, by their definitional factor which states, crimes involving younger victims tend to be looked at as a "normal" part of youth. They are looked at as minor and therefore not reported to the police as much. Secondly, by their jurisdictional factor, most incidents involving younger victims are handled by other authority, such as teachers, coaches, and parents rather than going directly to the police. Also, Kaukinen (2002) found that employed respondents are significantly more likely to call the police as compared to not seeking help. Employed respondents are more likely to feel a moral responsibility to report crimes to the police and are more often part of the older age group.

Sampson and Laub (1990) theorized that social ties to the adult institutions of informal social (e.g. family, community, work) deter criminal behavior over the life course despite delinquent and antisocial background. Their organizing principle derived from the central idea of social control theory-crime and deviance result when an individual's bond to society is weak or broken. Sampson and Laub emphasized the quality or strength of social ties and the occurrence or timing of discrete life events. Life-course theory implies that transitions or turning points, which including marriage and employment, can redirect the life-course. For example, 
Gottfredson and Hirschi (1990) argue that marriage per se does not increase social control, but a strong attachment to one's spouse and close emotional ties increase the social bond between individuals. Similarly, employment coupled with job stability, commitment, and ties to work should increase social control and lead to lower criminal behavior and higher reporting rates. This theory can be used to explain why older people who tend to have these strong social ties are more likely to report criminal behavior. Older respondents, who have these strong attachments, feel it is their social duty to report crimes to the police.

When sex was a controlling factor, female juvenile/young adults were significantly more likely to report their victimization than the other categories. The other relationship categories had non-significant effects: Crimes involving juveniles are no more likely to fear reprisal from offenders than adult victims, no more likely to treat the crime as a personal matter, and no more likely to look at a crime as too minor to report. Stanko (1995) says that those who admit they feel the safest are young men, and therefore are less likely to report their victimization to the police. Young women experience more severe abuse than men, leading them to seek help more often and they are also more likely to maintain large and dense social networks and therefore, frequently rely on their family and friends in dealing with other life events. So, it is not surprising that their victimizations that threaten their immediate social network are likely to lead to informal help seeking (Kaukinen 2002). Young men tend to avoid asking for help to live up to a "masculine" ideal, and their incidents tend to be looked at as trivial or minor and therefore do not get reported.

Gender of Victim

I predicted that violent crime victimizations would more likely be reported to the police when the victim is a female. Also, I predicted that crimes involving males would less likely be 
reported to the police because the crime was treated as a personal matter, and it was looked at as too minor of a crime. Finally, I predicted that females would be less likely to report because of a fear of reprisal. As predicted, many of the gender effects were supported and found to be significant. Crimes involving female victims were found more likely to be reported to the police after they were victimized. The findings are in accord with some research that suggests that women are more likely than men to notify the police (Gottfredson \& Gottfredson, 1988; Skogan, 1976). Males were more likely to say they did not report the victimization to the police because it was too minor of a crime. Females were more likely to say they did not report the victimization because of fear of reprisal, which shows to be significant. This finding can be supported with survey data which indicate that about three times as many women are afraid of crime than men (Erskine 1974). Stanko (1995) says that women report fear at levels that are three times that of men, yet women's recorded risk of personal violence is lower than males. Finally, males were no more likely than females to say they did not report the victimization to the police because it was a personal matter; it was found to be not statistically significant.

The nature of male crime often reflects lifestyle characteristics that implicate a victim's role in initiating or provoking violence. These may affect the ways in which crimes are viewed by male victims and subsequently shape their reactions to crime. Men's responses to violence also reflect traditional views toward gender and masculinity (Stanko \& Hobdell, 1993), and these have important implications for coping and seeking help in dealing with crime.

\section{Victim/Offender Relationship}

I predicted that victims who had a previous family or intimate relationship to the offender were less likely to report the victimization to the police compared to victims who never knew 
their offenders. Victims who know their offenders are more likely to say that the crime was too minor, a personal matter, or have a fear of reprisal. However, what I found was that victims whose offenders were a family member or intimate partner are slightly more likely to report the victimization to the police than victims whose offenders were strangers, $52.6 \%$ and $51.1 \%$ respectively. On the other hand, victims whose relationship to the offender is as a friend or acquaintance, are the least likely to report the crime to the police than the other two relationships, 34.3\%. This finding can be supported with Felson et. al (1999) which found that once people consider themselves to be victims of crime, they are just as likely to call the police on family members as they are on strangers.

As predicted, victims who have a family or intimate relationship with the offender are more likely than victims who do not know their offenders to say that the reason they did not report the victimization was because it was a personal matter. Violent acts committed by family members are likely to be tolerated because of the desire to continue the relationship and to keep the offender out of trouble (Felson et. al 1999). However, victims who said they did not know their offender were more likely to say that the reason they did not report the victimization to the police was because they saw the crime as minor, compared to victims who knew their offender. Also, the relationship the victim had with the offender had no significant effect on fear of reprisal as the reason for not reporting the victimization to the police. 


\section{CONCLUSION}

Previous research shows that victimizations involving juveniles are less likely to come to the attention of the police. I suggest this evidence is not surprising because child victimizations usually are brought to the attention of other officials. Victimizations involving juveniles are usually looked at as a more personal matter that can be handled through other means. Also, since these crimes usually involve juvenile offenders they are looked at as a minor crime. When the crime involves an adult offender, these victimizations are often not reported because of a fear of reprisal.

Prior research provides mixed evidence as to whether victims are reluctant to call the police when the offender is a family member or intimate partner. This is not surprising because victims have other reasons that may offset these inhibitory factors. My results suggest that the relationship to the offender only inhibits the victims to not report the victimization when they feel the crime is a personal matter. Victims who have a relationship with their offenders are only more likely to report when the reason is that the crime was serious.

Gender also played an important role in the victim's decision whether to notify the police of an incident. My results show that women are more likely than men to call the police because they have a fear of reprisal. Men are less likely to call the police because they think the crime was too minor to report. However, gender did not play an important role in the victim's decision to call the police because the crime was a personal matter. Neither females nor males were more likely to say they did not report the victimization because it was personal.

A limitation to this paper is that it only looks into three reasons for why violent crimes are not reported to the police. Future research could look into other reasons for not reporting crime and compare across age groups and to the sex of the victim to help understand the factors 
leading to delays in seeking help. This would help to address why victims seek help in the first place. This suggests that aside from asking respondents whether they sought help, victimization surveys need to ask respondents why they sought particular types of help. Understanding the reasons why victims report crimes, can help us understand what is holding others back. These factors can not only help us, but other authorities to understand why victims are reluctant to report violent victimizations to the police. If the authorities could understand who is the least likely to report and the reasons attributed, possible programs and centers could be set up for easier access of reporting for these victims.

Another limitation to my project is that type of crime is not used as an independent variable. Future works could look to isolate the different types of violent crime, and run multivariate analyses against reporting and reasons for not reporting. Victims of more serious violence should perceive greater benefit from police involvement than victims of less serious violence because their desire for protection and retribution should be greater. For example, prior research including Hashima and Finkelhor (1999) present findings that reveal that 26 percent of juvenile and adult victimizations equally resulted in victims sustaining injury. All together, existing evidence does seem to suggest that crimes against juveniles are just as serious as crimes against adults (Finkelhor and Ormrod 2001), which contests the assertion that incident-severity measures should mediate variation in police reporting between juvenile and adult victims, also while controlling for the sex of the victim.

An additional idea for future work is the effects of gender and the victim-offender relationship. These findings could help to elaborate and clarify the connection between gender and police reporting. Kaukinen (2002) found that Help-seeking strategies are unique to particular gender/victim-offender relationship categories. Women victimized by known offenders rely on 
family and friends and other alternative help sources. In contrast, men victimized by strangers most often do nothing, but some men who have been victimized by a stranger will call the police. Few men, however, go to family or friends for support if attacked by a stranger. These findings have important implications for the types of crimes most likely to be processed by the criminal justice system.

Moreover, gender and the victim-offender relationship determine the types of helpseeking strategies used by victims. Women are much more likely to seek help from family, friends, and social services agencies in dealing with crime (Kaukinen 2002). These findings are in accord with the wider help-seeking literature that suggests that the users of mental health, social services, and self-help groups tend to be female (Schonert-Reichl and Muller, 1996).

Finally, a last limitation is that my project only looked at the reasons for not reporting crimes to the police, therefore future projects could look at the reasons crimes were reported to the police, such as recover property or insurance, punish the offender, or advised to report. Greenberg and Ruback (1992) propose that three general processes underlie the decision to report property crimes: (a) a cognitively driven utilitarian or cost-benefit process, (b) an affectively driven process, and (c) a socially driven process. This model can be used in explaining the victims' decision to call the police for any crime.

First, a cost-benefit process is when victims weigh the expected benefits and costs of calling the police and then choose to notify the police when they believe that the potential rewards outweigh the potential costs (Gottfredson \& Gottfredson, 1980). In support of this reasoning, research shows that the greater the victim's monetary loss, the more likely the victim is to notify the police (Bureau of Justice Statistics, 2006). Presumably, the greater the loss, the 
more the victim stands to gain from reporting and thus the greater the victim's incentive for calling the police.

Secondly, although studies document the emotional trauma of criminal victimization (Greenberg \& Ruback, 1992), there is no research on the direct impact of emotion on victim decision making. Research suggests that emotional arousal might influence victims' attention, perceptions, thoughts, judgments, and interpretations, processing capacity, and processing strategies (Forgas, 2001). Alternatively, the presence of intense emotions may "automatically" activate well-learned behavioral responses with little or no mediating cognitive activity, such as when anger or fear induces victims to notify the police (Greenberg and Ruback, 1992).

Thirdly, from interviews with crime victims, a substantial number of such victims consult with others (e.g., family, friends, bystanders) when deciding whether or not to notify the police (Spelman \& Brown, 1981). Consistent with this reasoning, Greenberg and Ruback (1992), in a series of five laboratory experiments, demonstrated the powerful effect of social influence on victim decision making.

In conclusion, the decision-making process for victims is more complex then suggested. There are many factors that go through the minds of the victim when they are deciding to notify the police. Incidents involving men or the younger age group are more likely viewed as trivial or minor, compared to females, and therefore not brought to the attention of the police. These factors help us understand why victims are reluctant to report violent victimizations. 
APPENDIX: Tables

Table 1: Descriptive Statistics for Dependent and Independent Variables (N=1775)

Variable

Frequency

Percent

Dependent Variables

\begin{tabular}{lccl}
$\begin{array}{l}\text { Reported } \\
\text { Not }\end{array} \quad \begin{array}{l}\text { to Police } \\
\text { Reported to Police }\end{array}$ & 923 & 48.0 \\
\multicolumn{2}{c}{ Reasons for Not Reporting } & & 52.0 \\
Personal & Matter & 208 & 23.3 \\
Minor & Crime 175 & & 19.6 \\
Fear & of Reprisal & 87 & 9.8 \\
Other & 1305 & & 47.3
\end{tabular}

Independent Variables

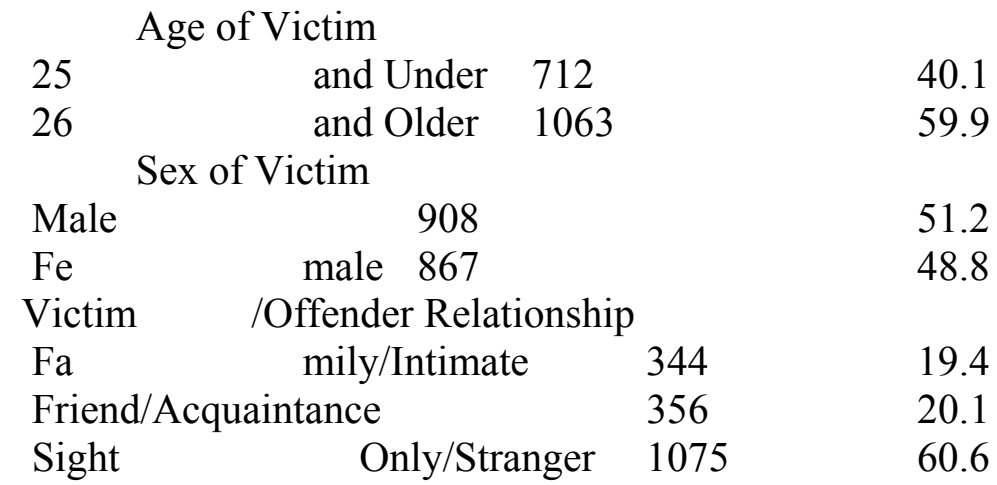

Other Variables

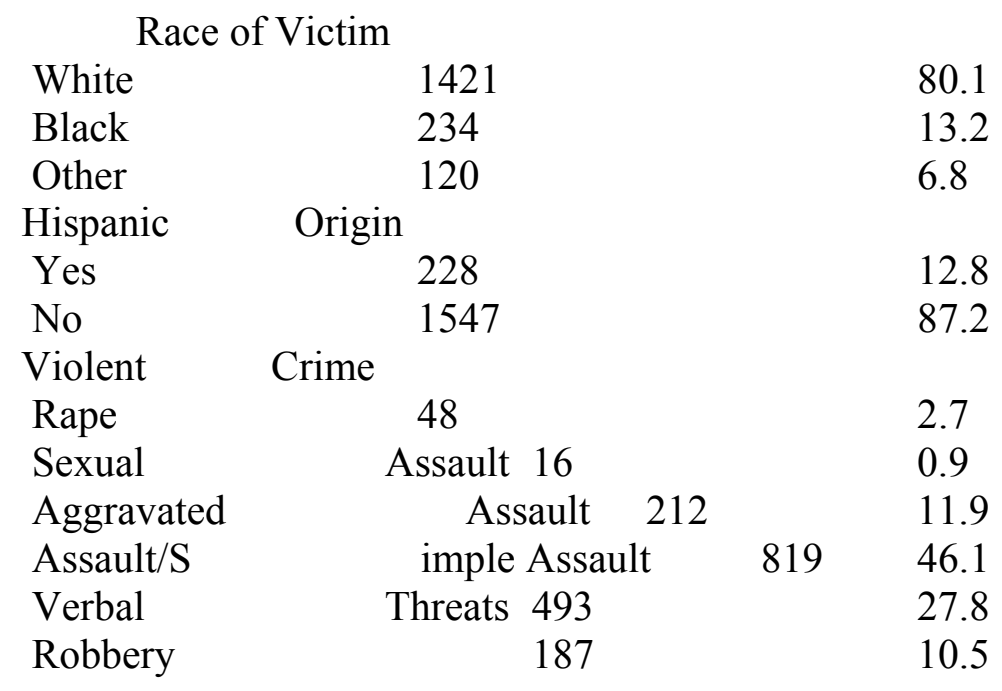


Table 2: Incidents Reported to Police by Age, Sex, and Relationship (N=1775)

\section{Age of Victim}

$$
\text { Frequency Percentage } x 2 \quad \text { Significance }
$$

25 and Under 288

40.1

26 and Older 564
$53.4 * * *$
$30.061 \quad .001$

Sex of Victim

$\begin{array}{lrrrrr}\text { Male } & 416 & 45.8 & & \\ \text { Fe } & \text { male } & 436 & 50.3 & 3.556 & .059\end{array}$

Victim/Offender Relationship

$\begin{array}{llllll}\text { Fa } & \text { mily/Intimate } & 181 & 52.6 & & \\ \text { Friend/Acquaintance } & 122 & 34.3 & & \\ \text { Sight } & \text { Only/Stranger } & 549 & 51.1^{* * *} & 33.884 & .001\end{array}$

Table 3: Reporting by Age and Sex (\%) (N=1775)

Sex of Victim

25 and Under*** 26 and Older

Male $\quad 36.3 \quad 52.5$

Fe male $44.3 \quad 54.2$

Table 4: Reasons for Non-reporting by Age, Sex, and Relationship (\%) (N=891)

Age of Victim

Personal Matter Minor Crime Fear of Reprisal

$25 \quad$ and Under 22.1

26 and Older 24.4

$21.0 \quad 10.5$

$18.5 \quad 9.1$

Sex of Victim
Male
24.4
$26.3 * * *$
12.0
6.1
Fe male 22.1
$13.9 * * *$

Victim/Offender Relationship

\begin{tabular}{lllllr} 
& \multicolumn{2}{c}{13.8} & \multicolumn{2}{c}{13.8} \\
Fa mily/Intimate & $33.3^{* * *}$ & \multicolumn{2}{c}{13.8} & 9.7 \\
Friend/Acquaintance & 26.9 & 13.7 & & \\
Sight & Only/Stranger & 18.6 & $24.2 * * *$ &
\end{tabular}


Table 5: Reasons for Non-reporting by Age and Sex (\%) (N=891)

Age of Victim

25 and Under

26 and Older

Male
Personal
Minor
Fear

$\mathrm{Fe} \quad$ male

Personal

Minor

Fear

\section{Significance}

$* .05$

$* * .01$

$* * * .001$

$\begin{array}{ccl}\text { Matter } & 20.9 & 27.9 \\ \begin{array}{c}\text { Crime } 28.5 \\ \text { of Reprisal }\end{array} & 8.5^{*} & 24.2 \\ & & 3.8\end{array}$

$\begin{array}{ccc}\text { Matter } & 23.8 & 20.8 \\ \begin{array}{c}\text { Crime } \\ \text { of Reprisal }\end{array} & 11.4 & 12.6 \\ & & 14.7\end{array}$




\section{References}

Bachman, Ronet. 1998. Factors Related to Rape Reporting Behavior and Arrest: New Evidence from the National Crime Victimization Survey. Criminal Justice and Behavior, 25(1), 829.

Black, D. (1976). The behavior of law. New York: Academic Press.

Block, Richard. 1974. Why notify the police: The victim's decision to notify the police of an assault. Criminology 11:555-569.

Bureau of Justice Statistics. (2007). Criminal victimization 2006: Changes 1998-2006 with trends 1993-2006. Washington, DC: U. S. Department of Justice.

Erskine, H. 1974. "The Polls: Fear of Crime and Violence." Public Opinion Quarterly 38(Spring):131-45.

Felson, Richard B. and Alison C. Cares. (2005). "Gender and the Seriousness of Assaults on Intimate Partners and Other Victims.” Journal of Marriage and Family. 67: 1182-1195.

Felson, Richard B., Steven F. Messner, and Anthony H. Hoskin. (1999). Victim-offender relationship and calling the police in assaults. Criminology 37:931-947.

Felson, Richard B., Steven F. Messner, Anthony H. Hoskin, and Glenn Deane. (2002). Reasons for reporting and not reporting domestic violence to the police. Criminology 40:617-647.

Finkelhor, David and Kathleen Kendall-Tackett. (1997). A Developmental Perspective on the Childhood Impact of Crime, Abuse \& Violent Victimization. Developmental 
Perspectives on Trauma: Theory, Research, and Intervention (pp. 1-32). New York: University of Rochester Press.

Finkelhor, David, Janis Wolak, and Lucy Berliner (2001). "Police Reporting and Professional Help for Child Victims: A Review". Child Maltreatment. 6(1): 17-30.

Finkelhor, David and Richard K. Ormrod (2001) Factors in the Underreporting of Crimes Against Juveniles. Child Maltreat. 6: 219.

Finkelhor, David and Richard Ormrod. (2000) "Characteristics of Crimes against Juveniles" Juvenile Justice Bulletin - NCJ179034. 1-11. Washington, DC: US Government Printing Office.

Finkelhor, David and Richard K. Ormrod. (1999). Reporting Crimes against Juveniles. Juvenile Justice Bulletin- NCJ178887. 1-11. Washington, DC: US Government Printing Office.

Gartner, R., \& Doob, A. (1994). Trends in criminal victimization: 1988-1993. Juristat, 14(13), 120.

Gottfredson, M. R. and Gottfredson, D. M. (1980). Decision making in criminal justice: Toward the rational exercise of discretion. Cambridge, MA: Ballinger.

Greenberg, Martin S., and Scott R. Beach. (2004). Property Crime Victims' Decision to Notify the Police: Social, Cognitive, and Affective Determinants. Law and Human Behavior. 28 (2): 177-186.

Greenberg, Martin S., and R. B. Ruback. (1992). After the crime: Victim decision making. New York: Plenum. 
Hart, Timothy C. and Callie Marie Rennison. (2003). Reporting Crime to Police, 1992-2000. Washington, DC: USGPO. NCJ 195710.

Hashima, Patricia and David Finkelhor (1999). Violent Victimization of Youth versus Adults in the National Crime Victimization Survey. Journal of Interpersonal Violence. 14(8): 799820.

Hawkins, Richard O. (1973). Who Called the Cops?: Decision to Report Criminal Victimization. Law and Society Review. 7 (3): 427-444.

Kaukinen, Catherine. (2002). The Help-Seeking Decisions of Violent Crime Victims

An Examination of the Direct and Conditional Effects of Gender and the VictimOffender Relationship. Journal of Interpersonal Violence. 17(4): 432-456.

Koss, M.P., Dinero, T.E., Siebel, C.A \& Cox, S.L. (1988). Stranger and acquaintance rape: Are there differences in the victim's experience? Psychology of Women Quarterly, 12, 1-24.

Laub, J. (1997). Patterns of criminal victimization. In R. Davis, A. Lurigio, \& W. Skogan (Eds.), Victims of crime (pp. 9-26). Thousand Oaks, CA: Sage.

Menard, Scott. (2002). Applied Logistic Regression Analysis. Thousand Oaks, CA: Sage.

Second edition.

Migliaccio, T. A. 2002. Abused Husbands: A Narrative analysis. Journal of Family Issues, 23 (1): 26-52.

Rollwagen, Heather. and Van Brunschot, Erin. (2007). Gender Differences in the Reporting of Intimate Partner Violence. Paper presented at the annual meeting of the AMERICAN 
SOCIETY OF CRIMINOLOGY. $<\mathrm{PDF}>.2009$ from

http://www.allacadem ic.com/meta/p201288_index.htm

Sampson, Robert J., and John H. Laub. 1990. Crime and Deviance over the Life Course: The salience of adult social bonds. American Sociological Review. 55: 609- 627.

Schonert-Reichl, K., \& Muller, J. (1996). Correlates of help-seeking in adolescence. Journal of Youth and Adolescence, 25(6), 705-731.

Singer, Simon I. 1988. Fear of reprisal and the failure of victims to report a personal crime. Journal of Quantitative Criminology. 4: 289-308.

Skogan, W. (1976). Citizen reporting of crime: Some national panel data. Criminology, 13(4), $535-549$.

Skogan, W. (1984). Reporting crimes to the police: The status of world research. Journal of Research in Crime and Delinquency. 21: 113-137.

Spelman, W., \& Brown, D. K. (1981). Calling the police: Citizen Reporting of Serious Crime. Washington, DC: Police Executive Research Forum.

Stanko, E., \& Hobdell, K. (1993). Assault on men: Masculinity and male victimization. British Journal of Criminology, 33(3), 400-415.

Stanko, Elizabeth. (1995). Women, Crime, and Fear. Annals of the American Academy of Political and Social Science. 539: 46-58.

Straus, Murray A., Richard J. Gelles, and Suzanne K. Steinmetz. 1980. Behind Closed Doors: Violence in the American family. Garden City, NJ: Anchor Books. 